\title{
Relation of the western North Pacific tropical cyclone genesis number to intraseasonal oscillation intensity
}

\author{
Renguang $\mathrm{Wu}^{1,2,3,{ }^{*}}$ and $\mathrm{Xi} \mathrm{Cao}{ }^{3}$ \\ ${ }^{1}$ School of Earth Sciences, Zhejiang University, Hangzhou, China \\ ${ }^{2}$ Southern Marine Science and Engineering Guangdong Laboratory (Zhuhai), Zhuhai, China \\ ${ }^{3}$ Center for Monsoon System Research, Institute of Atmospheric Physics, Chinese Academy of Sciences, Beijing, China
}

\section{Article history: \\ Received 3 March 2021 \\ Revised 9 May 2021 \\ Accepted 4 June 2021}

Keywords:

Tropical cyclone genesis number, ISO intensity, The western North Pacific, Spatial change in the relationship

\section{Citation:}

Wu, R. and X. Cao, 2021: Relation of the western North Pacific tropical cyclone genesis number to intraseasonal oscillation intensity. Terr. Atmos. Ocean. Sci., 32, 1141-1152, doi: 10.3319/ TAO.2021.06.04.02

\begin{abstract}
The present study investigates the relationship of the year-to-year variations in the tropical cyclone (TC) genesis number over the western North Pacific (WNP) to the intensity of 10-20-day and 30-60-day intraseasonal oscillations (ISOs) during 1979 - 2018. It is found that the relationship between the TC genesis number and ISO intensity differs largely among the four quadrants of the WNP. The TC number in the southeast quadrant of the WNP has a close relation to the ISO intensity, but the relation is mostly weak for the TC number in the other three quadrants of the WNP. More (less) TC number in the southeast quadrant of the WNP corresponds to a stronger (weaker) ISOs. This indicates that stronger ISOs or longer active phases of the ISOs provide a favorable condition for formation of more TCs. This modulation of the ISO intensity on the TC genesis number suggests an indirect way for influence of seasonal mean background on the year-to-year variations in the WNP TC number through the ISO intensity. Further analysis suggests that this indirect way is likely a more important manner for the influence of seasonal mean background on the yearto-year variations in the genesis TC number over the WNP.
\end{abstract}

\section{INTRODUCTION}

The western North Pacific (WNP) is an ocean basin with most tropical cyclones (TCs) annually over the world. The WNP TCs may lead to great socioeconomic losses in East Asia and Southeast Asian countries when they move westward or northwestward to make landfall near the coastal regions. Thus, the reason for the year-to-year variations in the TC genesis number over the WNP is an issue of many previous studies (e.g., Chan 2000; Chia and Ropelewski 2002; Wang and Chan 2002; Camargo and Sobel 2005; Chen et al. 2006).

The TC formation is subjected to the impacts of various environmental factors (Gray 1968). The role of seasonal mean atmospheric and oceanic states in the variations of the WNP TC number has been indicated in previous studies. TCs prefer to occur within the monsoon trough region (Ritchie and Holland 1999; Molinari and Vollaro 2013; Yo-

\footnotetext{
* Corresponding author

E-mail: renguang@zju.edu.cn
}

shida and Ishikawa 2013; Feng et al. 2014; Cao and Wu 2018a; Cao et al. 2020) where synoptic disturbances tend to develop. More TCs form east of $160^{\circ} \mathrm{E}$ during strong monsoon trough years than during weak monsoon trough years (Wu et al. 2012). The El Niño and La Niña events in the tropical central-eastern Pacific modulate the large-scale background of the TC genesis over the WNP, leading to a shift of the TC genesis location southeastward and northwestward, respectively (Chan 2000; Chia and Ropelewski 2002; Wang and Chan 2002).

Previous studies have shown the impacts of the intraseasonal oscillation (ISO) on the WNP TC occurrence ( $\mathrm{Li}$ ebmann et al. 1994; Maloney and Hartmann 2001; Kim et al. 2008; Camargo et al. 2009; Huang et al. 2011; Cao et al. 2012). More TCs tend to form in the wet/active phase of the ISOs (Kim et al. 2008; Huang et al. 2011; Zhao et al. 2015). Analysis shows that the disturbance at the TC occurrence is mostly due to the contributions of synoptic and intraseasonal components (Cao and Wu 2018b; Cao et al. 2018). As the ISO plays a role in the WNP TC genesis, the 
ISO intensity may be a factor in the WNP TC number variations. However, the contribution of the ISO intensity to the year-to-year variations in the WNP TC genesis number has not been investigated in the literature.

The seasonal mean not only serves as a background for the TC formation, but also modulates the ISO intensity (Wu and Cao 2017; Wu and Song 2018; Wang and Wu 2020). The 10-20-day ISOs tend to be intensified over the tropical WNP during the El Niño developing summers and the 3060-day ISOs tend to be stronger over the tropical WNP during the La Niña decaying summers (Wu and Cao 2017). As such, the ISO intensity change may serve as a medium in the influence of seasonal mean anomalies on the TC formation over the WNP. This indirect influence of seasonal mean on the WNP TC genesis variations via modulation of the ISO intensity has not been addressed in previous studies.

The present study focuses on the contribution of the ISO intensity to the year-to-year variations in the WNP TC genesis number. The direct effect and indirect effect of seasonal mean anomalies on the TC number variation are compared as well. Note that the year-to-year variations in the source, propagation and coupling with the convection of the ISOs may also affect the TC activity. The present study, however, only investigates the impact of the ISO intensity. As indicated by previous studies, the two ISOs, the 10-20day and 30-60-day time scales, display notable differences in the location of initiation and direction of propagation (Kajikawa and Yasunari 2005; Yang et al. 2008; Wang et al. 2009). The 30-60-day ISOs affect the tropical WNP through a northward or northeastward propagation from the eastern Indian Ocean and the Maritime Continent (Annamalai and Slingo 2001; Kemball-Cook and Wang 2001). The 10-20-day ISOs reach the WNP via a northwestward propagation from the equatorial western-central Pacific (Yang et al. 2008; Kikuchi and Wang 2009). Thus, the effects of the two ISOs on the WNP TC number variations are examined separately in the present analysis.

The WNP TC occurrence extends over a domain with $60^{\circ}$ longitudes and $30^{\circ}$ latitudes. As such, the environmental fields of the TC genesis are likely not uniform within the whole WNP basin. This indicates the necessity of examining the factors of the TC occurrence in different sectors of the WNP. It is shown that the TC number in the northwest and southeast parts of the WNP has an opposite relation to El Niño-Southern Oscillation (ENSO) (Wang and Chan 2002; Chen and Tam 2010; Kim et al. 2011; Zhan et al. 2014; Ha et al. 2015; Liu and Chen 2019; Liu et al. 2019). Thus, the present study examines the relationship of the TC genesis number variations to the ISO intensity in different WNP sectors.

The organization of the text is as follows. The data and methods are introduced in section 2 . Section 3 presents the spatial change in the relationship of the TC genesis number to the ISO intensity over the WNP. Section 4 addresses the effect of the ISO intensity on the variations of the TC number in the SE sector of the WNP. Section 5 compares the direct and indirect effects of seasonal mean on the TC number variations. Summary is provided in section 6 .

\section{DATA AND METHODS}

The TC number in the present study is derived from the TC best-track data of the Joint Typhoon Warning Center (JTWC), which is archived in the International Best Track Archive for Climate Stewardship (IBTrACS) v03r10 of the National Climate Data Center (Knapp et al. 2010). The TC genesis is determined when the maximum sustained wind speed reaches $33 \mathrm{kts}\left(\sim 17 \mathrm{~m} \mathrm{~s}^{-1}\right)$. The domain of TC genesis in the present analysis extends from $120^{\circ} \mathrm{E}$ to the dateline and from the equator to $30^{\circ} \mathrm{N}$. The present study counts the total TC number over June-November (hereafter JJASON), which is the TC season in the WNP region. The difference in the variations of the TC number between June to August (JJA) and September to November (SON) is not addressed in the present study.

The present study uses daily mean $850 \mathrm{hPa}$ winds and monthly mean wind, vertical motion and specific humidity from the National Centers for Environmental PredictionDepartment of Energy (NCEP-DOE) reanalysis (Kanamitsu et al. 2002). The reanalysis variables have a horizontal resolution of $2.5^{\circ}$ in latitude and longitude. The NCEP-DOE reanalysis is available from 1979 to the present and provided by the NOAA/OAR/ESRL Physical Science Department (PSD). The NCEP-DOE reanalysis variables were obtained from the web site at http://www.esrl.noaa.gov/psd/.

Monthly mean SST used in the present study is the NOAA Extended Reconstructed Sea Surface Temperature (ERSST) version 5 data (Huang et al. 2017). The ERSST data is available on a horizontal resolution of $2^{\circ} \times 2^{\circ}$ from 1854 to the present. The ERSST data were obtained via ftp://ftp.cdc.noaa.gov/.

In the present study, the genesis potential index (GPI) (Emanuel and Nolan 2004; Camargo et al. 2007) is used to consolidate the contributions of different environmental variables to the TC genesis. The GPI is calculated as follows:

$G P I=T 1 \times T 2 \times T 3 \times T 4$

where $T 1=\left|10^{5} \eta\right|^{3 / 2}, \quad T 2=\left(1+0.1 V_{\text {shear }}\right)^{-2}, \quad T 3=\left(\frac{H}{50}\right)^{3}$, $T 4=\left(\frac{V_{p o t}}{70}\right)^{3}, \eta$ is the absolute vorticity at lower-level $(850 \mathrm{hPa})\left(\mathrm{in} \mathrm{s}^{-1}\right), V_{\text {shear }}$ is the magnitude of the vertical wind shear between 850 and $200 \mathrm{hPa}$ (in m s${ }^{-1}$ ), $H$ is the relative humidity at mid-level $(700 \mathrm{hPa})$ in percent, and $V_{p o t}$ is the potential intensity (in $\mathrm{m} \mathrm{s}^{-1}$ ).

An analysis of the barotropic energy conversion to the synoptic scale disturbances is performed in the present study based on the following equation: 
$\frac{\partial K_{\text {baro }}{ }^{\prime}}{\partial t}=-u^{\prime} v^{\prime} \frac{\partial \bar{u}}{\partial y}-u^{\prime 2} \frac{\partial \bar{u}}{\partial x}-v^{\prime 2} \frac{\partial \bar{v}}{\partial y}-u^{\prime} v^{\prime} \frac{\partial \bar{v}}{\partial x}$

where $\frac{\partial K_{\text {baro }}{ }^{\prime}}{\partial t}$ is the time rate of change of the kinetic energy, $(\bar{u}, \bar{v})$ are the background zonal and meridional winds, and $\left(u^{\prime}, v^{\prime}\right)$ are the synoptic zonal and meridional wind components. The four terms in the right-hand-side represent the barotropic energy conversion related to the meridional shear of zonal wind, the zonal convergence of zonal wind, and the meridional convergence of meridional flow, the zonal shear of meridional flow, respectively. The synoptic wind components are derived using original daily mean minus a 9-day running mean. Each term on the right hand side of the above equation is calculated by averaging the product of daily quantities during June through November (JJASON) in a specific year.

The intensity of the ISOs is measured using the kinetic energy of intraseasonal variations of daily winds at $850 \mathrm{hPa}$. First, the intraseasonal variations of $850 \mathrm{hPa}$ daily winds at 10-20-day and 30-60-day time bands are obtained by using a 9-day running mean minus a 21-day running mean and a 29-day running mean minus a 61-day running mean applied to daily mean winds, respectively. Note that the running mean approach allows the extension of the filtered time series when new data are added without repeating the filtering for the whole time series. Then, the kinetic energy of 10-20day and 30-60-day intraseasonal wind variations is calculated for the time period during 1 June through 30 November in each year. Last, the average values of the kinetic energy during JJASON of a specific year are obtained to represent the intensity of two ISOs in that year. In the following, we use KE1 and KE2 to denote the intensity of 10-20-day and 30-60-day ISOs during JJASON, respectively. Note that the intensity of ISOs in the present study differs from the amplitude of individual ISO events.

The present analysis separates the WNP into four sectors based on $15^{\circ} \mathrm{N}$ latitude and $150^{\circ} \mathrm{E}$ longitude. This allows the four sectors to have nearly equal areas. The above separation is the same as Chen and Tam (2010), Tao and Lan (2017), and Wu et al. (2019, 2020). The four sectors are termed as northwest (NW), northeast (NE), southwest (SW), and southeast (SE) quadrant, respectively. The relationship of the TC number to the ISO intensity and seasonal mean is examined for the four quadrants separately.

Correlation and regression analysis is used in the present analysis. The statistical significance of the correlation is estimated based on the Student's $t$ test. Composite analysis is used to obtained common anomalies for a specific type of years. The statistical significance of the difference of composite anomalies between two types of years is estimated using the two tailed Student's $t$ test. The two sample Kolmogorov-Smirnov test (Kolmogorov 1933; Smirnov 1948) is used to examine the statistical significance of the difference between two cumulative probability density functions (PDFs).

\section{SPATIAL CHANGE IN THE RELATIONSHIP OF THE TC NUMBER TO THE ISO INTENSITY}

In this section, we examine the relationship of the TC number in the four quadrants of the WNP to the ISO intensity. The purpose is to investigate whether the relationship differs among the four quadrants. Figures 1 - 2 show the correlation coefficient of grid point KE1 and KE2 with areamean TC number in the whole WNP and the four quadrants during JJASON for the period 1979 - 2018.

The TC number in the whole WNP region displays moderate positive correlation with the 10-20-day ISO intensity over most of the domain (Fig. 1a). However, there is a pronounced difference of the correlation among the TC numbers in the four quadrants. The TC number in the SE quadrant has a high positive correlation with the 10-20-day ISO intensity extending northwestward from the equatorial central Pacific $\left(160^{\circ} \mathrm{E}-140^{\circ} \mathrm{W}\right)$ (Fig. 1e). The NE quadrant TC number displays a moderate positive correlation in a subtropical region (Fig. 1c). The correlation with the SW quadrant TC number is small except for a few limited regions (Fig. 1d). The correlation with the NW quadrant TC number has a negative correlation extending northwestward from the equatorial central Pacific (Fig. 1b).

There are several features on Fig. 1 that are worthy of discussion. The first feature is that the correlation with the SE, NE, and NW quadrant TCs displays a southeast-northwest band structure. This is related to the origin and propagation of the 10-20-day ISOs. The 10-20-day ISOs tend to originate from the equatorial western Pacific and propagate northwestward to the WNP (Kikuchi and Wang 2009). The second feature is that the correlation with the SE and NW quadrant TCs is opposite. This is due to an opposite variation of the TCs in the two quadrants. The correlation coefficient of TCs in the SE and NW quadrants is -0.42 for the period $1979-2018$. The third feature is that the positive correlation band with the NE quadrant TC is confined to north of $15^{\circ} \mathrm{N}$ and extends from southwest part of the SE quadrant to the NW quadrant. This indicates that the NE quadrant TC is only influenced by the 10-20-day ISOs that propagates along higher latitudes. The extension of positive correlation to the NW quadrant may be explained by the consistency of the 10-20-day ISO intensity change along the propagation path. The weak correlation in the northeast part of the NE quadrant is likely due to few TC activity and/or weak 10-20day ISO activity.

The correlation of the 30-60-day ISO intensity with the TC number tends to display features similar to that of the 10-20-day ISO intensity. The correlation with the whole WNP TC number is dominated by positive values (Fig. 2a). Large positive correlation with the SE quadrant TC number 
(b)

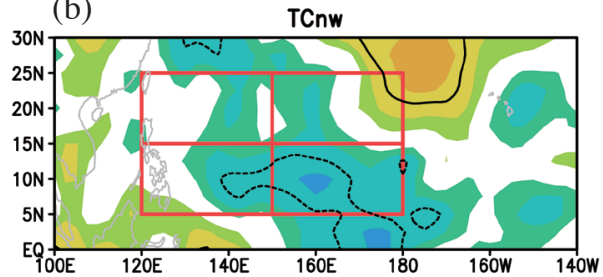

(d)

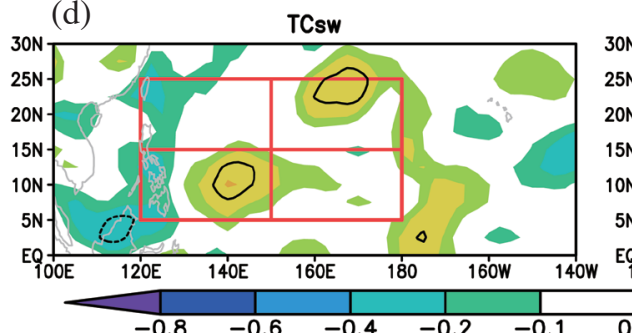

(a) cor(KE1) JJASON 1979-2018

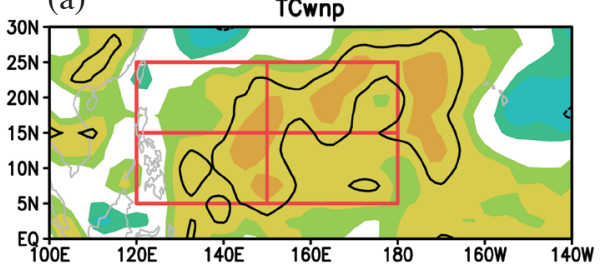

(c)

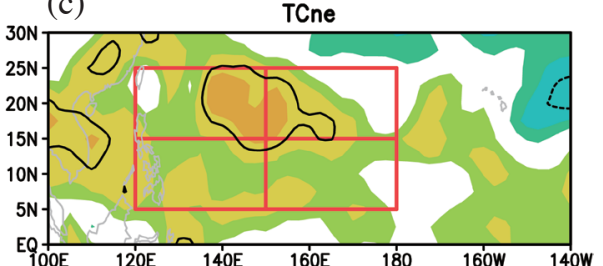

(e)

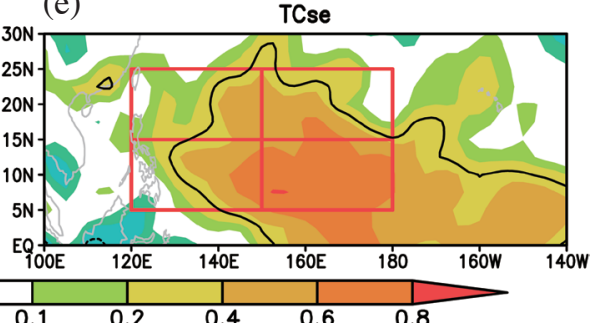

Fig. 1. Correlation coefficient of grid point 10-20-day ISO intensity with the TC number in (a) whole WNP, (b) NW, (c) NE, (d) SW, and (e) SE quadrants of the WNP during JJASON for the period 1979 - 2018. Thick lines denote correlation coefficient significant at the 95\% confidence level. The four quadrants are denoted by the red lines.
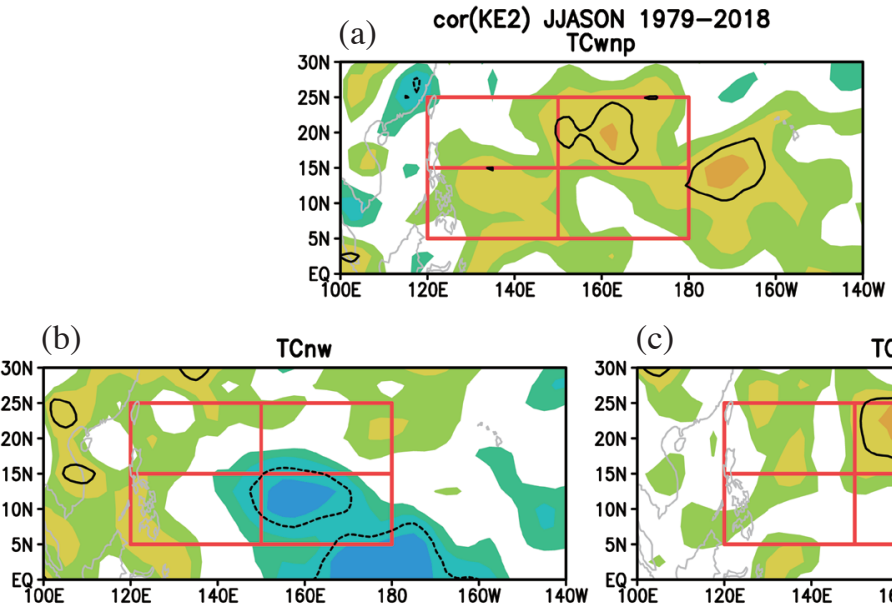

(c)

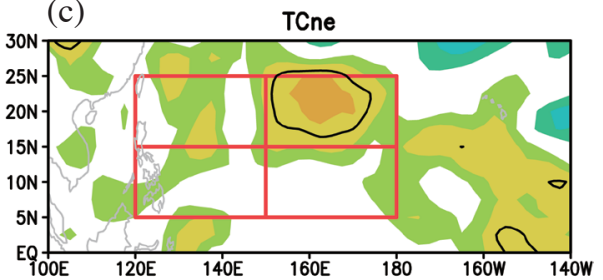

(d)

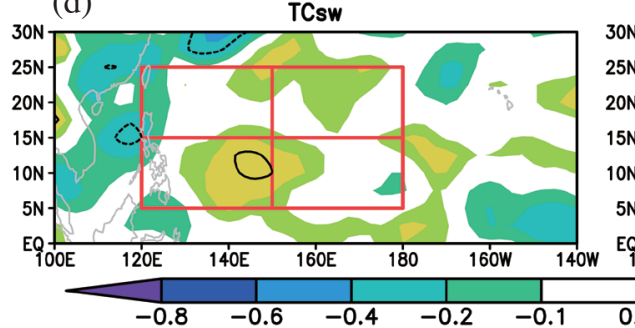

(e)

TCse

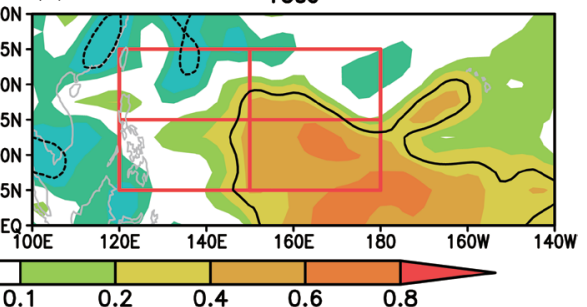

Fig. 2. Correlation coefficient of grid point 30-60-day ISO intensity with the TC number in (a) whole WNP, (b) NW, (c) NE, (d) SW, and (e) SE quadrants of the WNP during JJASON for the period 1979 - 2018. Thick lines denote correlation coefficient significant at the $95 \%$ confidence level. The four quadrants are denoted by the red lines. 
extends northwestward from the equatorial central Pacific (Fig. 2e). Nearly opposite correlation is seen with the NW quadrant TC number (Fig. 2b). In comparison, the correlation in the SE quadrant with the 30-60-day ISO intensity is somewhat smaller compared to that with the 10-20-day ISO intensity. A feature to note is that the NE quadrant TC has a moderate positive correlation with the 30-60-day ISO intensity in the same region (Fig. 2c). A similar feature is seen for the SW quadrant TC but with a smaller positive correlation (Fig. 2d).

The difference of the TC number-ISO intensity relationship among the four quadrants of the WNP is further confirmed by the correlation coefficient between the areamean ISO intensity and TC number (Table 1). The correlation coefficient of area mean in the SE quadrant reaches 0.76 and 0.64 , respectively, for the 10-20-day and 30-60day ISOs, both of which are significant over the $99.9 \%$ confidence level. The correlation of area mean in the whole WNP region is significant at the $95 \%$ confidence level for the 10-20-day ISO. The correlation of area mean in the NE quadrant is significant at the $95 \%$ confidence level for the 30-60-day ISO. The difference of the above relationship among the four quadrants of the WNP indicates that it is necessary to investigate reasons of the TC number variations in different sectors separately.

\section{EFFECT OF THE ISO INTENSITY IN THE TC NUMBER VARIATION IN THE SE SECTOR}

The comparison of the relationship in the previous section indicates that the TC number in the SE quadrant is prominently modulated by the ISO intensity, which is distinct from the TC number in the other three quadrants. In this section, we focus on illustrating the effect of the ISO intensity on the TC number in the SE quadrant of the WNP.

We first compare the temporal evolution of the JJASON TC number and ISO intensity averaged over the SE quadrant of the WNP (Fig. 3). A prominent coherent yearto-year changes are seen between the TC number and the intensity of the two ISOs in most years during the analysis period. Based on the time series of the JJASON TC number, we select 11 years $(1980,1986,1987,1991,1992,1994$, $1997,2002,2004,2015,2018)$ with the TC number of 4 or more and 13 years $(1981,1988,1989,1998,1999,2005$, $2006,2007,2008,2010,2011,2016,2017)$ with no TC occurrence in the SE quadrant. Then, we conduct a composite analysis of the JJASON ISO intensity in the two types of years. The intensity of the 10-20-day ISO shows a large positive and significant difference over the WNP between the two types of years (Fig. 4a). The largest difference is centered around $10^{\circ} \mathrm{N}$ and $150^{\circ} \mathrm{E}$, reaching over $2 \mathrm{~m}^{2} \mathrm{~s}^{-2}$. The intensity of the 30-60-day ISO displays a positive difference as well (Fig. 4b), but with a much smaller difference and over a smaller region compared to the 10-20-day ISO. The discrepancy is likely related to the difference in the region of source and propagation of the two ISOs. The 10-20-day ISOs tend to originate from the equatorial western Pacific and propagate northwestward to the WNP (Kikuchi and Wang 2009), whereas the 30-60-day ISOs tend to propagate northeastward from the Maritime Continent to the WNP (Kemball-Cook and Wang 2001). The above differences suggest that the contribution of the 10-20-day ISO may be larger than that of the 30-60-day ISO. This is confirmed by a partial correlation analysis for TC, KE1, and KE2 in the SE quadrant. The correlation coefficient between TC and KE1 changes from 0.74 to 0.54 after removing the signal of KE2. The correlation coefficient between TC and KE2 drops from 0.64 to -0.13 . The results indicate that the positive correlation between TC and KE2 is likely due to the coherent variation of KE1 and KE2 (a positive correlation of 0.90 for the period $1979-2018)$.

The contribution of the 10-20-day and 30-60-day ISOs is confirmed by an analysis of barotropic energy conversion to synoptic scale disturbances. There are more barotropic energy conversion from the two ISOs to synoptic disturbances in more than less TC years (Fig. 5). In comparison, the overall barotropic energy conversion from the 10-20day ISO is larger than that from the 30-60-day ISO. The conversion from the $10-20$-day ISO is larger east of $145^{\circ} \mathrm{E}$ (Fig. 5a) and that from the 30-60-day ISO is larger west of $150^{\circ} \mathrm{E}$ (Fig. $5 \mathrm{~b}$ ). The term associated with the meridional shear of zonal wind has a leading contribution and the term associated with the zonal convergence of zonal wind is secondary from both the 10-20-day and 30-60-day ISOs (figures not shown). The term associated with the meridional convergence of meridional wind of the 10-20-day ISO has a negative contribution, so is the term associated with the zonal shear of meridional wind of the 30-60-day ISO (figures not shown).

The increased intensity of the ISOs signifies a larger amplitude of intraseasonal wind fluctuations or a longer period of active phases of the ISOs. To illustrate this, we compare the PDF distribution of the natural logarithm of daily kinetic energy of the two ISOs in the more and less SE quadrant TC number years (Fig. 6). The PDF is obtained for the grid points falling within the SE quadrant. Note that the PDF is calculated for the natural logarithm of the kinetic energy since the kinetic energy does not follow the normal distribution. The PDF displays an obvious shift to negative values in less than more TC years. The mean values of the natural logarithm of the kinetic energy of the 10-20-day (3060-day) ISO are -0.85 and $-0.17(-1.59$ and -0.77$)$, respectively, in less and more TC years. The mean values of the kinetic energy of the 10-20-day (30-60-day) ISO are 1.15 and 1.95 (0.57 and 1.00), respectively, in less and more TC years. It indicates that the two ISOs tend to be stronger and/ or the active phases of the ISOs tend to be longer in more than less TC years. To estimate whether the two PDFs are 
Table 1. Correlation coefficient between TC number and KE1 or KE2 during JJASON in the whole WNP and four sectors of the WNP for the period $1979-2018$. Symbol *, **, and $* * *$ denotes correlation coefficient reaching the $95 \%, 99 \%$, and $99.9 \%$ confidence level, respectively.

\begin{tabular}{c|ccccc}
\hline & whole & NW & NE & SW & SE \\
\hline TC-KE1 & $0.36^{*}$ & -0.20 & 0.17 & 0.14 & $0.76^{* * *}$ \\
TC-KE2 & 0.29 & 0.19 & $0.35^{*}$ & 0.15 & $0.64^{* * *}$ \\
\hline
\end{tabular}

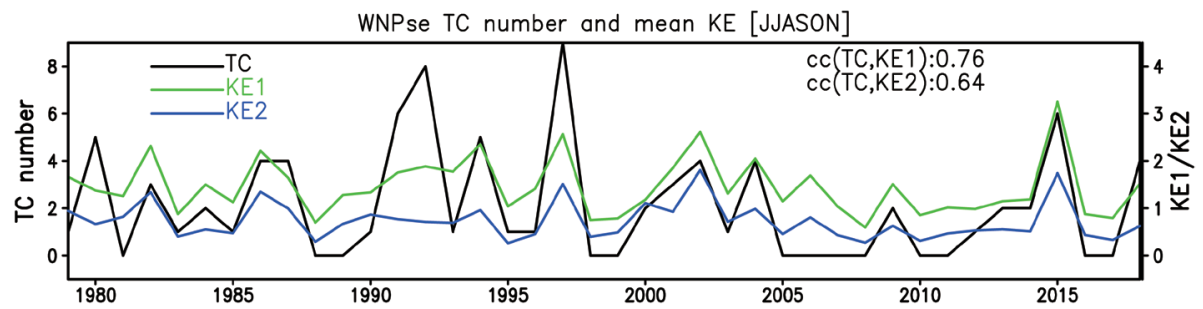

Fig. 3. The TC number (black curve) and area-mean 10-20-day and 30-60-day ISO intensity (green and blue curves, $\mathrm{m}^{2} \mathrm{~s}^{-2}$ ) averaged in the SE quadrant of the WNP during JJASON for the period 1979 - 2018. The numbers on the top-right denote the correlation coefficients between the TC number and the ISO intensity.

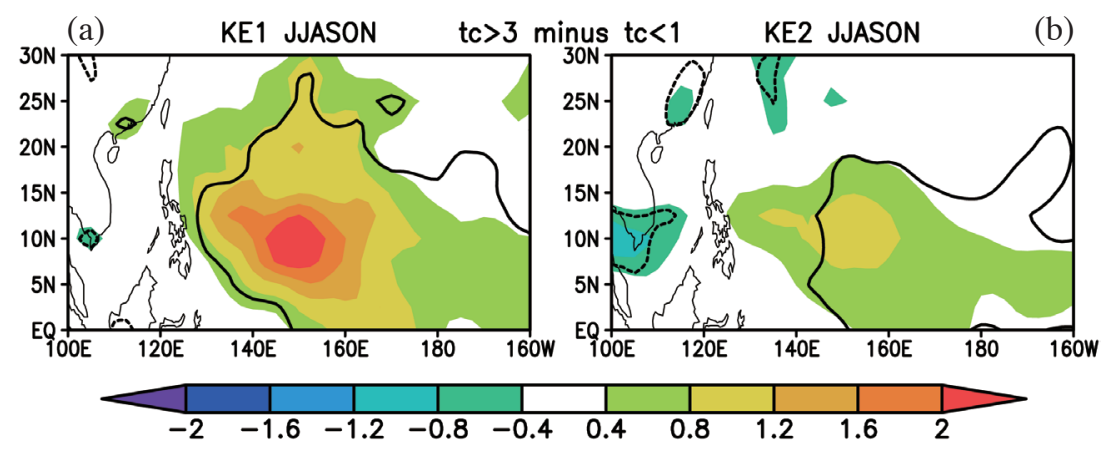

Fig. 4. Difference of composite JJASON (a) 10-20-day and (b) 30-60-day ISO intensity $\left(\mathrm{m}^{2} \mathrm{~s}^{-2}\right.$ ) between years of the JJASON TC number in the SE quadrant of the WNP of more than 3 and less than 1. The thick lines denote that the difference is significant at the $95 \%$ confidence level.

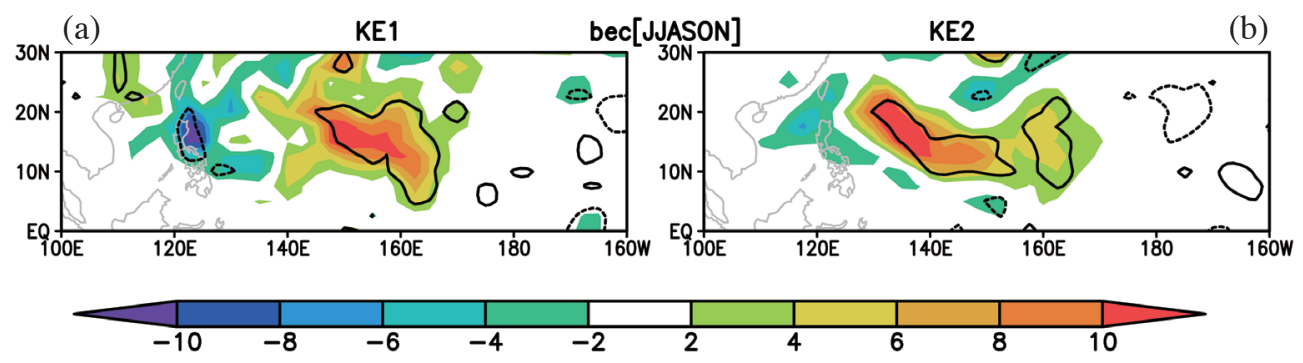

Fig. 5. Differences of composite JJASON anomalies $\left(10^{-6} \mathrm{~m}^{2} \mathrm{~s}^{-3}\right)$ of sum of four terms in the equation of barotropic kinetic energy conversion associated with (a) 10-20-day and (b) 30-60-day ISO between years of the JJASON TC number in the SE quadrant of the WNP of more than 3 and less than 1 . The thick lines denote that the difference is significant at the $95 \%$ confidence level. 
(a) WNPse KE1 JJASON daily (\%)

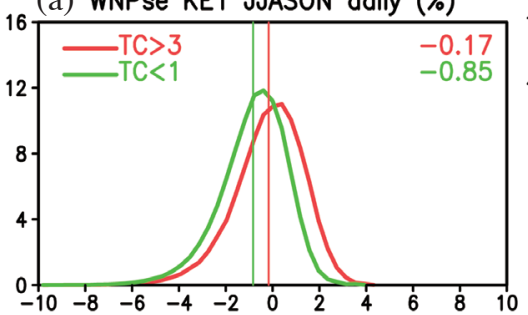

Fig. 6. The PDFs of grid-point natural logarithm of the JJASON kinetic energy of (a) 10-20-day and (b) 30-60-day ISO within the SE quadrant of the WNP for years of the JJASON TC number in the SE quadrant of the WNP of more than 3 (red) and less than 1 (green). The vertical lines and numbers in the top-right denote the mean values of the PDFs.

significantly different from each other between more and less TC years, we calculate the cumulative PDFs of the natural logarithm of the kinetic energy of the two ISOs in more and less TC years (Fig. 7). According to the KolmogorovSmirnov statistic, the maximum difference of cumulative PDFs between more and less TC years exceeds the 95\% and 99\% confidence level, respectively, for the 10-20-day and 30-60-day ISO.

Previous studies have shown that more TCs tend to form in the active phase of the ISOs (Kim et al. 2008; Huang et al. 2011; Zhao et al. 2015) and the intraseasonal components of the environmental variables contribute largely to the disturbances at the TC occurrence (Cao and $\mathrm{Wu} 2018 \mathrm{~b}$; Cao et al. 2018). Our results indicate that stronger ISOs and/ or longer active phases of the ISOs provide a favorable condition for the formation of more TCs in the SE quadrant of the WNP. In contrast, weaker ISOs and/or shorter active phases of the ISOs may lead to a reduction in the TC number in the SE quadrant of the WNP.

\section{ROLE OF THE ISO INTENSITY IN THE EFFECT OF SEASONAL MEAN ON THE TC NUMBER VARIATION}

The year-to-year variations in the TC genesis over the WNP are usually attributed to seasonal mean anomalies (Chan 2000; Chia and Ropelewski 2002; Wang and Chan 2002; Wu et al. 2012; Feng et al. 2014; Cao and Wu 2018a; Cao et al. 2020). It is also shown that the seasonal mean anomalies modulate the intensity of the ISOs over the WNP (Wu and Cao 2017; Wu and Song 2018; Wang and $\mathrm{Wu} 2020)$. The analysis in the previous sections indicate the effect of the ISO intensity on the variations of the TC number in the SE quadrant of the WNP. Together, it suggests that the seasonal mean effects on the TC variation have two different ways. One is a direct modulation of the environment of TC genesis. The other is an indirect way through modulating the ISO intensity. In this section, we first compare the environment fields corresponding to the TC number and area-mean ISO intensity in the SE quadrant of the WNP. Then, we demonstrate the modulation of seasonal mean on the ISO intensity. Last, we illustrate the role of the ISO intensity in the effect of seasonal mean on the TC number variation. There are several quantities involved in the modulation of seasonal mean environmental field, including lower-level vorticity, mid-tropospheric vertical motion, mid-level specific humidity, vertical shear of wind between lower and upper levels and SST. We synthesize the effects of those quantities using the GPI in the following analysis.

The GPI anomalies display very similar feature corresponding to the TC number and the 10-20-day and 3060-day ISO intensity in the SE quadrant of the WNP. Large positive and significant GPI anomalies extend northwestward from the equatorial central Pacific in more TC years as well as in stronger ISO years (Fig. 8). Negative GPI anomalies are seen over the SW quadrant of the WNP and subtropical WNP. The good correspondence of the GPI anomalies suggests that the seasonal mean environment modulates both the TC number and the ISO intensity in the SE quadrant of the WNP.

We compare the PDFs of the natural logarithm of the kinetic energy of the two ISOs to demonstrate the modulation of seasonal mean anomalies on the ISO intensity. Based on the time series of area-mean JJASON GPI anomalies in the SE quadrant of the WNP, we select 13 positive (1980, 1982, 1990, 1991, 1997, 2002, 2003, 2004, 2006, 2009. $2014,2015,2018)$ and $15(1981,1983,1984,1988,1989$, 1995, 1996, 1998, 1999, 2007, 2008, 2010, 2011, 2012, 2017) negative GPI anomaly years based on the criterion of 0.5 standard deviation. The PDF of the natural logarithm of the kinetic energy of the two ISOs is calculated for the grid points within the SE quadrant of the WNP in positive and negative GPI anomaly years. Apparently, the PDF shifts to negative values when the GPI anomaly is negative (Fig. 9). The mean values of the natural logarithm of the kinetic energy of the 10-20-day (30-60-day) ISO is -0.83 and -0.26 (-1.62 and -0.88), respectively, in negative and positive GPI anomaly years. The mean values of the kinetic energy of the 10-20-day (30-60-day) ISO is 1.06 and 1.77 (0.54 and 1.01), respectively, in negative and positive GPI anomaly years. The results indicate that the two ISOs tend to be stronger and/or have a longer active phases when GPI is larger, but 
(a) WNPse KE1 JJASON daily (\%)

(b) WNPse KE2 JJASON daily (\%)

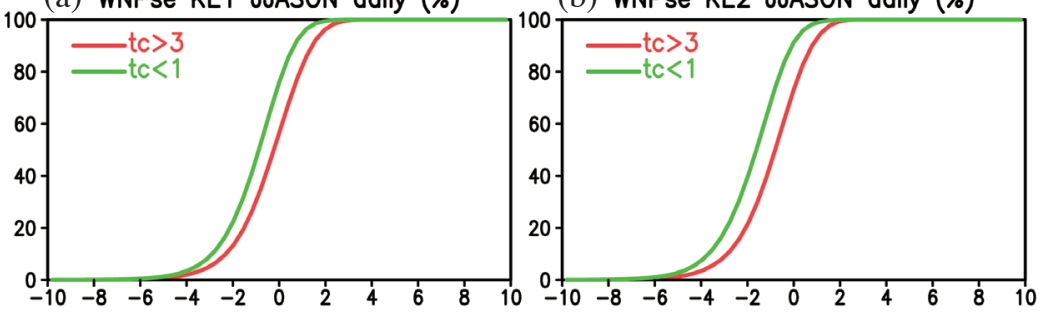

Fig. 7. The cumulative PDFs of grid-point natural logarithm of the JJASON kinetic energy of (a) 10-20-day and (b) 30-60-day ISO within the SE quadrant of the WNP for years of the JJASON TC number in the SE quadrant of the WNP of more than 3 (red) and less than 1 (green).

(a) TCse

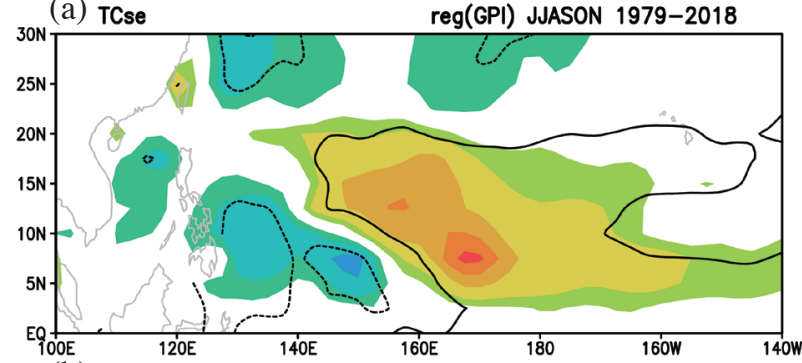

(b) KE1se

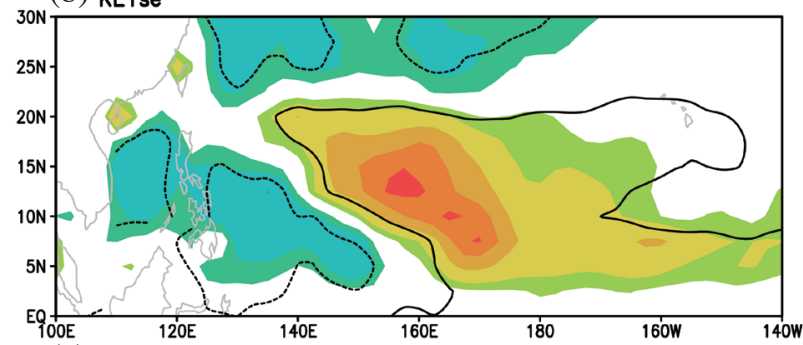

(c) KE2se

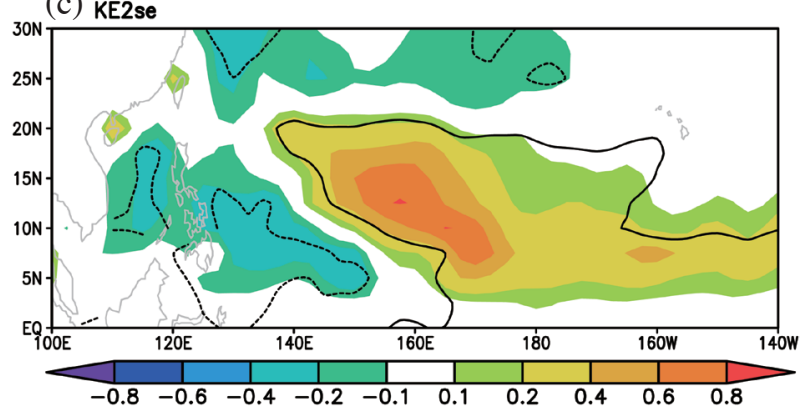

Fig. 8. GPI anomalies obtained by regression against the (a) TC number and area-mean (b) 10-20-day and (c) 30-60-day ISO intensity in the SE quadrant of the WNP during JJASON for the period 1979 - 2018. Thick lines denote that the anomalies are significant at the $95 \%$ confidence level.

(a) WNPse KE1 JJASON daily (\%)

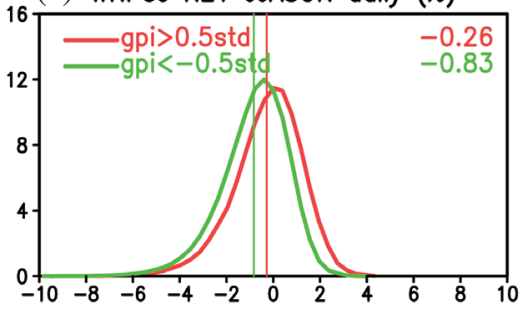

(b) WNPse KE2 JJASON daily (\%)

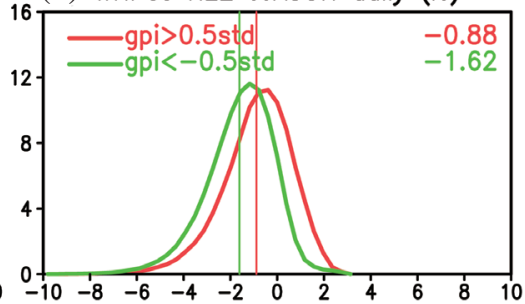

Fig. 9. The PDFs of grid-point natural logarithm of the JJASON kinetic energy of (a) 10-20-day and (b) 30-60-day ISO within the SE quadrant of the WNP for years of area-mean JJASON GPI in the SE quadrant of the WNP of more than 0.5 standard deviation (red) and less than - 0.5 standard deviation (green). The vertical lines and numbers in the top-right denote the mean values of the PDFs. 
weaker and/or have a shorter active phases when GPI is smaller. This feature is similar to that corresponding to the more and less TC number years (Fig. 5).

We perform a partial correlation analysis of area means to illustrate the role of the ISO intensity in the effect of seasonal mean on the TC number variations. For the area means in the SE quadrant, the correlation coefficient is 0.63 between the TC number and GPI, 0.75 between GPI and KE1, and 0.70 between GPI and KE2 (Table 2). All the three correlation coefficients are significant above the 99.9\% confidence level. The partial correlation coefficient between the TC number and GPI drops to 0.14 after removing the KE1 effect and 0.34 after removing the KE2 effect. The large drop of the correlation coefficients excluding the KE1 and KE2 effects indicates an important role of the ISO intensity in the influence of the seasonal mean on the TC number variation.

\section{SUMMARY}

Previous studies have attributed the year-to-year variations in the TC genesis number over the WNP to seasonal mean changes that modulate the large-scale environment of the TC genesis. Studies have also shown differences in the TC genesis between active and inactive phases of the ISOs over the WNP. The present study investigates the influence of the ISO intensity on the year-to-year variations in the TC genesis number over the WNP. It is found that the relationship between the WNP TC genesis number and ISO intensity differs largely among the four sectors of the WNP. The TC number in the SE quadrant of the WNP has a close relationship to both the 10-20-day and 30-60-day ISO intensity, whereas the TC number in the other three quadrants of the WNP does not show a good relationship with the intensity of the two ISOs.

Composite analysis shows that the 10-20-day ISO intensity has a larger difference between the more and less TC number years than the 30-60-day ISO intensity. A comparison of the PDF of logarithm of the kinetic energy of the two ISOs indicates that more TC number tends to form in the SE quadrant of the WNP when the ISOs are stronger and/or the active phases of the ISOs are longer. This correspondence suggests that stronger ISOs and/or longer active phases of the ISOs provide a favorable condition for the intensification of disturbances, which leads to a higher probability for the disturbances to develop into TCs.

The effect of the ISO intensity on the TC number variations serves as an alternative way for the influence of seasonal mean on the WNP TC number. Our partial correlation analysis shows that the correlation between the TC number and seasonal mean GPI becomes small after removing the effect of the ISO intensity. This suggests that the indirect influence of seasonal mean through the modulation of the ISO intensity is likely more important than the influence of seasonal mean on the TC genesis through the modulation of the large-scale environmental background.

Several previous studies noted that the TC-related wind fields may contribute to the variance of ISOs (e.g., Hsu et al. 2008; Aiyyer et al. 2012; Bi et al. 2015). Thus, as issue is whether the contributions of the ISO intensity to the TC activity obtained in the present analysis is contaminated by the TC-related winds. To address this issue, we conduct a parallel analysis after the TC vortex is removed from the $850 \mathrm{hPa}$ wind fields. The technique of Kurihara et al. (1995) is used in removing the TC vortex, following Hsu et al. (2008) and Bi et al. (2015). The employed procedure is the same as Bi et al. (2015). The results remain the same after the removal of TC vortex from the $850 \mathrm{hPa}$ wind fields though there are minor quantitative differences. Thus, we conclude that the TC signal does not alter the contributions of the ISO intensity to the TC variations.

The differences of the TC number-ISO intensity relationship among the four quadrants of the WNP indicate the necessity to distinguish the four quadrants in the investigation of the factors of the variations of the TC number in the WNP, consistent with Wu et al. $(2019,2020)$. An issue is why the TC number in the other three quadrants of the WNP has a weak relation to the ISO intensity. We note that the correlation between the TC number and area-mean GPI is prominent only in the SE quadrant, so is the correlation between the area-mean GPI and ISO intensity (Table 2). This appears to suggest that the role of the ISO intensity may be a factor in the spatial change in the link of the TC number with seasonal mean environment. Note, however, that the correlation between area-mean lower-level vorticity and ISO intensity is high in all the four quadrants though it is largest in the SE quadrant (Table 2). This indicates that the ISO intensity is closely related to seasonal mean lower-level vorticity anomalies. The ISO intensity may also subject to impacts of remote forcing. Further investigation is needed to understand the spatial change in the role of the ISO intensity in connecting the WNP TC number to the remote forcing.

Table 2. Correlation coefficient between TC number and GPI, between GPI and KE1 or KE2, between TC number and lower-level vorticity (Vort), and between lower-level vorticity (Vort) and KE1 or KE2 during JJASON in the whole WNP and four sectors of the WNP for the period 1979-2018. Symbol *, **, and *** denotes correlation coefficient reaching the $95 \%, 99 \%$, and $99.9 \%$ confidence level, respectively.

\begin{tabular}{c|ccccc}
\hline & whole & NW & NE & SW & SE \\
\hline TC-GPI & 0.13 & -0.06 & $0.34 *$ & 0.03 & $0.63 * * *$ \\
GPI-KE1 & $0.45^{*}$ & 0.28 & 0.31 & -0.24 & $0.75 * * *$ \\
GPI-KE2 & $0.38^{*}$ & 0.13 & 0.00 & -0.08 & $0.70^{* * *}$ \\
TC-Vort & $0.45^{*}$ & 0.16 & 0.21 & $0.36^{*}$ & $0.71 * * *$ \\
Vort-KE1 & $0.72 * * *$ & $0.45^{* *}$ & $0.39^{*}$ & $0.56^{* * *}$ & $0.81 * * *$ \\
Vort-KE2 & $0.58^{* * *}$ & $0.38^{*}$ & $0.33^{*}$ & $0.33^{*}$ & $0.79 * * *$ \\
\hline
\end{tabular}


Acknowledgements Comments of two anonymous reviewers are appreciated. This study is supported by the National Natural Science Foundation of China grants (41775080 and 41721004). The IBTrACS data were obtained from http://www.ncdc.noaa.gov/ibtracs/index.php. The NCEP-DOE reanalysis data were obtained from http:// www.esrl.noaa.gov/psd/.

\section{REFERENCES}

Aiyyer, A., A. Mekonnen, and C. J. Schreck, 2012: Projection of tropical cyclones on wavenumber-frequencyfiltered equatorial waves. J. Clim., 25, 3653-3658, doi: 10.1175/JCLI-D-11-00451.1. [Link]

Annamalai, H. and J. M. Slingo, 2001: Active/break cycles: Diagnosis of the intraseasonal variability of the Asian summer monsoon. Clim. Dyn., 18, 85-102, doi: 10.1007/s003820100161. [Link]

Bi, M., T. Li, X. Shen, and M. Peng, 2015: To what extent the presence of real-strength tropical cyclones influences the estimation of atmospheric intraseasonal oscillation intensity? Atmos. Sci. Lett., 16, 438-444, doi: 10.1002/asl.579. [Link]

Camargo, S. J. and A. H. Sobel, 2005: Western North Pacific tropical cyclone intensity and ENSO. J. Clim., 18, 2996-3006, doi: 10.1175/jcli3457.1. [Link]

Camargo, S. J., K. A. Emanuel, and A. H. Sobel, 2007: Use of a genesis potential index to diagnose ENSO effects on tropical cyclone genesis. J. Clim., 20, 4819-4834, doi: $10.1175 /$ jcli4282.1. [Link]

Camargo, S. J., M. C. Wheeler, and A. H. Sobel, 2009: Diagnosis of the MJO modulation of tropical cyclogenesis using an empirical index. J. Atmos. Sci., 66, 30613074, doi: 10.1175/2009jas3101.1. [Link]

Cao, X. and R. Wu, 2018a: Simulations of development of tropical disturbances associated with the monsoon trough over the western North Pacific. Atmos. Sci. Lett., 19, e801, doi: 10.1002/asl.801. [Link]

Cao, X. and R. Wu, 2018b: Comparison of different time scale contributions to tropical cyclone genesis over the western North Pacific in 2015 and 2016. J. Meteorol. Soc. Jpn., 96, 317-336, doi: 10.2151/jmsj.2018-038. [Link]

Cao, X., P. Huang, G. Chen, and W. Chen, 2012: Modulation of western North Pacific tropical cyclone genesis by intraseasonal oscillation of the ITCZ: A statistical analysis. Adv. Atmos. Sci., 29, 744-754.

Cao, X., R. Wu, and M. Bi, 2018: Contributions of different time-scale variations to tropical cyclogenesis over the western North Pacific. J. Clim., 31, 3137-3153, doi: 10.1175/JCLI-D-17-0519.1. [Link]

Cao, X., R. Wu, N. Wei, and Y. Dai, 2020: Location of the preferred region for tropical cyclogenesis in strong monsoon trough pattern over the western North Pacif- ic. J. Meteorol. Soc. Jpn., 98, 637-654, doi: 10.2151/ jmsj.2020-034. [Link]

Chan, J. C. L., 2000: Tropical cyclone activity over the western North Pacific associated with El Niño and La Niña events. J. Clim., 13, 2960-2972, doi: 10.1175/1520-0442(2000)013<2960:TCAOTW>2.0. $\mathrm{CO} ; 2$. [Link]

Chen, G. and C.-Y. Tam, 2010: Different impacts of two kinds of Pacific Ocean warming on tropical cyclone frequency over the western North Pacific. Geophys. Res. Lett., 37, L01803, doi: 10.1029/2009GL041708. [Link]

Chen, T.-C., S.-Y. Wang, and M.-C. Yen, 2006: Interannual variation of the tropical cyclone activity over the western North Pacific. J. Clim., 19, 5709-5720, doi: 10.1175/JCLI3934.1. [Link]

Chia, H. H. and C. F. Ropelewski, 2002: The interannual variability in the genesis location of tropical cyclones in the northwest Pacific. J. Clim., 15, 2934-2944, doi: 10.1175/1520-0442(2002)015<2934:TIVITG>2.0. CO;2. [Link]

Emanuel, K. A. and D. S. Nolan, 2004: Tropical cyclone activity and the global climate system. 26th Conference on Hurricanes and Tropical Meteorology, Session 10A, Tropical Cyclones and Climate, Miami, FL, American Meteorological Society, 240-241.

Feng, T., G.-H. Chen, R.-H. Huang, and X.-Y. Shen, 2014: Large-scale circulation patterns favourable to tropical cyclogenesis over the western North Pacific and associated barotropic energy conversions. Int. J. Climatol., 34, 216-227, doi: 10.1002/joc.3680. [Link]

Gray, W. M., 1968: Global view of the origin of tropical disturbances and storms. Mon. Weather Rev., 96, 669700, doi: 10.1175/1520-0493(1968)096<0669:GVOT OO>2.0.CO;2. [Link]

Ha, Y., Z. Zhong, X. Yang, and Y. Sun, 2015: Contribution of East Indian Ocean SSTA to western North Pacific tropical cyclone activity under El Niño/La Niña conditions. Int. J. Climatol., 35, 506-519, doi: 10.1002/ joc.3997. [Link]

Hsu, H.-H., C.-H. Hung, A.-K. Lo, C.-C. Wu, and C.W. Hung, 2008: Influence of tropical cyclones on the estimation of climate variability in the tropical western North Pacific. J. Clim., 21, 2960-2975, doi: 10.1175/2007JCLI1847.1. [Link]

Huang, B., P. W. Thorne, V. F. Banzon, T. Boyer, G. Chepurin, J. H. Lawrimore, M. J. Menne, T. M. Smith, R. S. Vose, and H.-M.Zhang, 2017: Extended reconstructed sea surface temperature, version 5 (ERSSTv5): Upgrades, validations, and intercomparisons. J. Clim., 30, 8179-8205, doi: 10.1175/JCLI-D-16-0836.1 . [Link]

Huang, P., C. Chou, and R. Huang, 2011: Seasonal modulation of tropical intraseasonal oscillations on tropical cyclone geneses in the western North Pacific. J. Clim., 
24, 6339-6352, doi: 10.1175/2011JCLI4200.1. [Link]

Kajikawa, Y. and T. Yasunari, 2005: Interannual variability of the 10-25- and 30-60-day variation over the South China Sea during boreal summer. Geophys. Res. Lett., 32, L04710, doi: 10.1029/2004GL021836. [Link]

Kanamitsu, M., W. Ebisuzaki, J. Woollen, S.-K. Yang, J. J. Hnilo, M. Fiorino, and G. L. Potter, 2002: NCEPDOE AMIP-II Reanalysis (R-2). Bull. Amer. Meteorol. Soc., 83, 1631-1644, doi: 10.1175/BAMS-83-11-1631. [Link]

Kemball-Cook, S. and B. Wang, 2001: Equatorial waves and air-sea interaction in the boreal summer intraseasonal oscillation. J. Clim., 14, 2923-2942, doi: 10.1175/1520-0442(2001)014<2923:EWAASI >2.0. CO;2. [Link]

Kikuchi, K. and B. Wang, 2009: Global perspective of the quasi-biweekly oscillation. J. Clim., 22, 1340-1359, doi: $10.1175 / 2008$ jcli2368.1. [Link]

Kim, H.-M, P. J. Webster, and J. A. Curry, 2011: Modulation of North Pacific tropical cyclone activity by three phases of ENSO. J. Clim., 24, 1839-1849, doi: 10.1175/2010JCLI3939.1. [Link]

Kim, J.-H., C.-H. Ho, H.-S. Kim, C.-H. Sui, and S. K. Park, 2008: Systematic variation of summertime tropical cyclone activity in the western North Pacific in relation to the Madden-Julian oscillation. J. Clim., 21, 11711191, doi: 10.1175/2007jcli1493.1. [Link]

Knapp, K. R., M. C. Kruk, D. H. Levinson, H. J. Diamond, and C. J. Neumann, 2010: The International Best Track Archive for Climate Stewardship (IBTrACS). Bull. Amer. Meteorol. Soc., 91, 363-376, doi: 10.1175/2009bams2755.1. [Link]

Kolmogorov, A., 1933: Sulla determinazione empirica di una lgge di distribuzione. Inst. Ital. Attuari, Giorn., 4, 83-91.

Kurihara, Y., M. A. Bender, R. E. Tuleya, and R. J. Ross, 1995: Improvements in the GFDL hurricane prediction system. Mon. Weather Rev., 123, 2791-2801, doi: 10.1175/1520-0493(1995)123<2791:IITGHP>2.0. CO;2. [Link]

Liebmann, B., H. H. Hendon, and J. D. Glick, 1994: The relationship between tropical cyclones of the western $\mathrm{Pa}$ cific and Indian Oceans and the Madden-Julian oscillation. J. Meteorol. Soc. Jpn., 72, 401-412, doi: 10.2151/ jmsj1965.72.3_401. [Link]

Liu, Y. and D. Chen, 2019: An interdecadal change in the interannual variability of boreal summer tropical cyclone genesis frequency over the western North Pacific around the early 1990s. Theor. Appl. Climatol., 137, 1843-1853, doi: 10.1007/s00704-018-2710-3. [Link]

Liu, Y., P. Huang, and G. Chen, 2019: Impacts of the combined modes of the tropical Indo-Pacific sea surface temperature anomalies on the tropical cyclone genesis over the western North Pacific. Int. J. Climatol., 39,
2108-2119, doi: 10.1002/joc.5938. [Link]

Maloney, E. D. and D. L. Hartmann, 2001: The MaddenJulian oscillation, barotropic dynamics, and north $\mathrm{Pa}-$ cific tropical cyclone formation. Part I: Observations. J. Atmos. Sci., 58, 2545-2558, doi: 10.1175/15200469(2001)058<2545:TMJOBD>2.0.CO;2. [Link]

Molinari, J. and D. Vollaro, 2013: What percentage of western North Pacific tropical cyclones form within the monsoon trough? Mon. Weather Rev., 141, 499-505, doi: 10.1175/mwr-d-12-00165.1. [Link]

Ritchie, E. A. and G. J. Holland, 1999: Large-scale patterns associated with tropical cyclogenesis in the western Pacific. Mon. Weather Rev., 127, 2027-2043, doi: 10.1175/1520-0493(1999)127<2027:LSPAWT>2.0. CO;2. [Link]

Smirnov, N., 1948: Table for estimating the goodness of fit of empirical distributions. Ann. Math. Statist., 19, 279281, doi: 10.1214/aoms/1177730256. [Link]

Tao, L. and Y. Lan, 2017: Inter-decadal change of the interannual relationship between the frequency of intense tropical cyclone over the western North Pacific and ENSO. Int. J. Climatol., 37, 4880-4895, doi: 10.1002/ joc.5129. [Link]

Wang, B. and J. C. L. Chan, 2002: How strong ENSO events affect tropical storm activity over the western North Pacific. J. Clim., 15, 1643-1658, doi: 10.1175/1520-0442(2002)015<1643:HSEEAT>2.0. $\mathrm{CO} ; 2$. [Link]

Wang, B., F. Huang, Z. Wu, J. Yang, X. Fu, and K. Kikuchi, 2009: Multi-scale climate variability of the South China Sea monsoon: A review. Dyn. Atmos. Oceans, 47, 15-37, doi: 10.1016/j.dynatmoce.2008.09.004. [Link]

Wang, Y. and R. Wu, 2020: Patterns and factors of interannual variations of boreal summer intraseasonal oscillation intensity over tropical western North Pacific. Clim. Dyn., 54, 2085-2099, doi: 10.1007/s00382-01905100-9. [Link]

Wu, L., Z. Wen, R. Huang, and R. Wu, 2012: Possible linkage between the monsoon trough variability and the tropical cyclone activity over the western North Pacific. Mon. Weather Rev., 140, 140-150, doi: 10.1175/ MWR-D-11-00078.1. [Link]

Wu, R. and X. Cao, 2017: Relationship of boreal summer 10-20-day and 30-60-day intraseasonal oscillation intensity over the tropical western North Pacific to tropical Indo-Pacific SST. Clim. Dyn., 48, 3529-3546, doi: 10.1007/s00382-016-3282-5. [Link]

$\mathrm{Wu}, \mathrm{R}$. and L. Song, 2018: Spatiotemporal change of intraseasonal oscillation intensity over the tropical IndoPacific Ocean associated with El Niño and La Niña events. Clim. Dyn., 50, 1221-1242, doi: 10.1007/ s00382-017-3675-0. [Link]

Wu, R., Y. Yang, and X. Cao, 2019: Respective and combined impacts of regional SST anomalies on tropical 
cyclogenesis in different sectors of the western North Pacific. J. Geophys. Res., 124, 8917-8934, doi: 10.1029/2019JD030736. [Link]

Wu, R., X. Cao, and Y. Yang, 2020: Interdecadal change in the relationship of the western North Pacific tropical cyclogenesis frequency to tropical Indian and North Atlantic Ocean SST in early 1990s. J. Geophys. Res., 125, e2019JD031493, doi: 10.1029/2019JD031493. [Link]

Yang, J., B. Wang, and B. Wang, 2008: Anticorrelated intensity change of the quasi-biweekly and 30-50-day oscillations over the South China Sea. Geophys. Res. Lett., 35, L16702, doi: 10.1029/2008GL034449. [Link]
Yoshida, R. and H. Ishikawa, 2013: Environmental factors contributing to tropical cyclone genesis over the western North Pacific. Mon. Weather Rev., 141, 451-467, doi: 10.1175/MWR-D-11-00309.1. [Link]

Zhan, R., Y. Wang, and L. Tao, 2014: Intensified impact of East Indian Ocean SST anomaly on tropical cyclone genesis frequency over the western North Pacific. J. Clim., 27, 8724-8739, doi: 10.1175/JCLID-14-00119.1. [Link]

Zhao, H., X. Jiang, and L. Wu, 2015: Modulation of northwest Pacific tropical cyclone genesis by the intraseasonal variability. J. Meteorol. Soc.Jpn., 93, 81-97, doi: 10.2151/jmsj.2015-006. [Link] 